\title{
Comparison of Soil-Structure Interaction Methods between Chinese Mainland Building Seismic Design Code and Taiwanese Code
}

\author{
Kun $\mathrm{Xia}^{1,2}$ and Lingxin Zhang ${ }^{2, *}$ \\ ${ }^{1}$ Lanzhou Institute of Seismology, China Earthquake Administration, Lanzhou 730000, China \\ ${ }^{2}$ Institute of Engineering Mechanics, China Earthquake Administration; Key Laboratory of Earthquake Engineering and \\ Engineering Vibration of China Earthquake Administration, Harbin 150080, China \\ ${ }^{*}$ Corresponding author
}

\begin{abstract}
Along with the accumulation of earthquake damage experience and researches on earthquake, the standard of building seismic design is modified all the time to be more objectively and scientifically. The soil-structure interaction method is significant but still qualitative, so a detailed comparison between Chinese Mainland code and Taiwanese code was carried out, including application scope, reduction method of earthquake action, and the change of reduction factor with height Analysis results show that Chinese code method need to be improved following: 1) provide the structure type which should be considered soil-structure interaction effect clearly; 2) select structural period and damping ratio as variables to consider the influence of SSI to seismic force and give a specific value for reference; 3) consider the second-order effect of SSI and give modified lateral displacement of the structure.
\end{abstract}

Keywords-building seismic design code; soil-structure interaction; seismic shear reduction method; modified proposal

\section{INTRODUCTION}

Research on seismic response of soil-structure interaction is a gradual rising significant topic in recent decades with the rapid development of the numerical calculating technology and the seismic test technique for structures. It is a frontier research field of earthquake engineering and structural dynamics involving basic assumptions of seismic calculation. The traditional seismic design often assumes that the foundation is rigid body, without considering the dynamic effect of soilstructure interaction. This assumes has a lot of convenience for anti-seismic calculation. With a large number of major projects such as high-rise building, nuclear power plant and offshore platform to build, if not to consider the soil and these large structures as a whole in the seismic design, it is difficult to make the right and conform to the actual seismic design, and lead to wrong or inaccurate result. Therefore, we should consider the problem of soil-structure interaction as far as possible in anti-seismic calculation.

Building seismic design code is a normative standard of building seismic design; it is the generalization and summarization of the research on theory and practice for many years. Due to the geological environment, architectural form and economic conditions make the emphases and specific provisions of the codes are different, but the theoretical bases of provisions are worth research. With the deepening of the crossstrait cooperation and exchanges, the earthquake engineering researchers of both sides can learn from each other the successful experience. It will push for in-depth progress and development of bilateral cooperation in structural seismic areas. In order to optimize seismic design method considered soilstructure interaction effect, a detailed comparison between Chinese mainland code and Taiwanese code was given. The similarities and differences of two codes are summarized. The direction of modifying current Chinese mainland seismic design code and the content of this paper are clarified. The purpose of this study is to provide some reference for modified provision of Chinese mainland seismic code about the problem of soil-structure interaction.

\section{ChINESE MAINLAND SEISMIC CODE}

Chinese mainland uses the "Code for seismic design of buildings (2010)" [1]. It stipulated that in the seismic computation of a structure, in general, the subsoil-structure interaction may be ignored; if the subsoil-structure interaction of reinforced concrete tall buildings for Intensity 8 and 9 and with Site-class III or IV is need to consider, that shall comply with following requirements:

(1) The tall building structures shall with box-type or a relatively rigid raft foundation or box-pile foundation; and the fundamental period of the structure is within the scope of 1.2 to 5 times of the characteristic period of Site.

(2) If the subsoil-structure interaction is considered for those structures, the horizontal seismic shear forces assumed for rigid base may be reduced in accordance with the following provisions, and the storey drift may be calculated according to the reduced storey shear force.

- In structures with height-width-ratio less than 3, the reduction factor of horizontal seismic shear of each floor may be determined by following Equation 1:

$$
\psi=\left(\frac{T_{1}}{T_{1}+\Delta T}\right)^{0.9}
$$


where: $\psi=$ seismic shear reduction factor considering the subsoil-structure interaction. $T_{1}=$ the fundamental period of the structure, which determined by assumption of the rigid base. $\Delta T=$ the additional period after considering the subsoilstructure interaction, that may be determined from Table I.

TABLE I. ADDITIONAL PERIOD (S)

\begin{tabular}{|c|c|c|}
\hline Intensity & Site-class III & Site-class IV \\
\hline 8 & 0.08 & 0.20 \\
\hline 9 & 0.10 & 0.25 \\
\hline
\end{tabular}

- $\quad$ For structures whose height-width-ratio is not less than 3 , the seismic shear of the structural bottom may be reduced according to the above clause, that of the top may not reduced, and that of the middle floors may be reduced according to the linear interpolation values.

(3) The reduced horizontal shear of all floors shall satisfy the requirements of Equation 2:

$$
V_{e k i}>\lambda \sum_{j=1}^{n} G_{j}
$$

where: $V_{e k i}=$ the i-th floor shear corresponding to horizontal seismic action characteristic value. $\lambda=$ shear factor, it shall not less than values in Table II; for the weak location of vertical irregular structure, these values shall also be multiplied by the amplifying factor of 1.15. $G_{j}=$ the representing value of gravity load in $\mathrm{j}$-th floor of the structure.

TABLE II. MINIMUM SEISMIC SHEAR FACTOR VALUE OF A FLOOR

\begin{tabular}{|c|c|c|c|c|}
\hline Structures & $\begin{array}{c}\text { Intensity } \\
\mathbf{6}\end{array}$ & $\begin{array}{c}\text { Intensity } \\
\mathbf{7}\end{array}$ & $\begin{array}{c}\text { Intensity } \\
\mathbf{8}\end{array}$ & $\begin{array}{c}\text { Intensity } \\
\mathbf{9}\end{array}$ \\
\hline $\begin{array}{c}\text { Structures with } \\
\text { obvious torsion } \\
\text { effect or } \\
\text { fundamental period } \\
\text { is less than 3.5s }\end{array}$ & 0.008 & $\begin{array}{c}0.016 \\
(0.024)\end{array}$ & $\begin{array}{c}0.032 \\
(0.048)\end{array}$ & 0.064 \\
\hline $\begin{array}{c}\text { Structures with } \\
\text { fundamental period } \\
\text { greater than 3.5s }\end{array}$ & 0.006 & $\begin{array}{c}0.012 \\
(0.018)\end{array}$ & $\begin{array}{c}0.024 \\
(0.036)\end{array}$ & 0.048 \\
\hline
\end{tabular}

Notes: 1) The values may be selected through interpolation method for structures whose basic period is between 3.5s and 5s. 2) Values in the brackets are used at the regions with basic seismic acceleration as $0.15 \mathrm{~g}$ and $0.30 \mathrm{~g}$ respectively.

\section{TAIWANESE SEISMIC CODE}

Taiwan uses the "Seismic design specifications for buildings (2011)” [2]. It stipulated that because of the structure, basement structure and foundation soil interaction, the equivalent spring damping ratio is incongruity, it shall calculate the composite vibration damping ratio according to the credible theoretical. When the damping ratio of structure is different from the $5 \%$, it can be determined by table III. Damping correction coefficient $B_{s}$ and $B_{1}$ may be reduced according to the linear interpolation values. And the spectral acceleration coefficient of short periods and 1.0 second periods need to be adjust to $S_{D S} / B_{s}$ and $S_{D 1} / B_{1}$. At the same time,
Taiwanese code has given the allowable relative lateral displacement angle of between floors.

Where $B_{s}=$ damping correction coefficient of short periods. $\quad B_{1}=$ damping correction coefficient of 1.0 second periods. $S_{D S}=$ the spectral acceleration coefficient of short periods. $S_{D 1}=$ the spectral acceleration coefficient of 1.0 second periods.

TABLE III. CORRECTION COEFFICIENT OF DAMPING RATIO (THE LINEAR INTERPOLATION VALUES)

\begin{tabular}{|c|c|c|}
\hline Effective damping ratio $\boldsymbol{\xi ( \% )}$ & $B_{s}$ & $B_{1}$ \\
\hline$<2$ & 0.80 & 0.80 \\
\hline 5 & 1.00 & 1.00 \\
\hline 10 & 1.33 & 1.25 \\
\hline 20 & 1.60 & 1.50 \\
\hline 30 & 1.79 & 1.63 \\
\hline 40 & 1.87 & 1.70 \\
\hline$>50$ & 1.93 & 1.75 \\
\hline
\end{tabular}

\section{THE SCOPE OF APPLICATION}

Chinese mainland code has too many restrictions for these buildings which considering the soil-structure interaction, and the structure of the regulation not enough clear or specific. So it is difficult for engineers in practice. However, Taiwanese code did not give specific requirements for these buildings, in principle all structures need to consider the impact of soilstructure interaction. This paper suggests that Chinese mainland code should be combined with using conditions of earthquake shear reduction method, to comprehensive give specific buildings which considering the soil-structure interaction.

\section{THE REDUCTION METHOD OF EARTHQUAKE SHEAR}

Chinese mainland code and Taiwanese code are based on the response spectrum method in the reduction calculations of earthquake shear, which use the adjusted dynamic parameters to determine seismic influence coefficient on the response spectrum [3]. But two codes have differences in the reduction calculation process of earthquake shear, dynamic modification parameters and so on.

\section{A. Computing Method}

Figure I shows the reduction method of earthquake shear of two codes [4]. It can be seen that two codes in the process of calculation are not very complicated, but Chinese mainland code is relatively simple on operation. In fact, no one is willing to go to multifarious operation in the heavy and complex process of buildings seismic design in addition to the special necessary. In this regard, Chinese mainland code has a certain advantage. On the other hand, Taiwanese code according to the actual situation of structural system to calculate the earthquake shear, the calculation process contains various influencing factors of the soil-structure interaction. But Chinese mainland code does not consider the influence of the foundation form and embedment method. So, the Chinese mainland code has flaws in this field. 
Mainland code

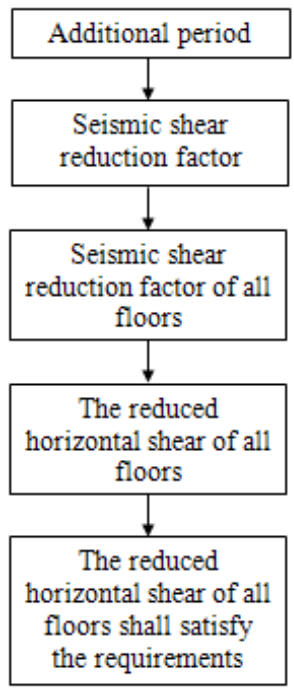

Taiwan code

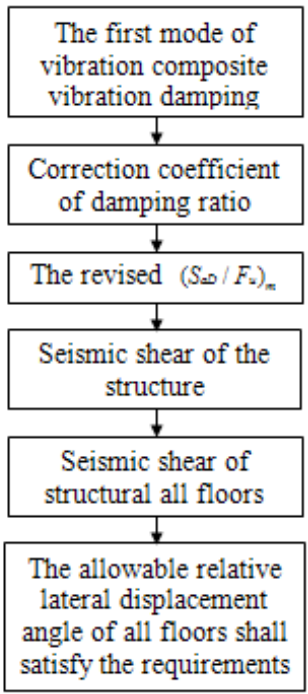

FIGURE I.

THE REDUCTION METHOD OF EARTHQUAKE SHEAR

\section{B. Correction Parameters}

Chinese mainland code selects natural period of structure as variable to consider the influence of SSI. While Taiwanese code selects damping ratio of structure as variable. And these two codes have given parameter variables with lookup table of statistical significance. Such as the table of "Additional period" in Chinese mainland code and "Correction coefficient of damping ratio" in Taiwanese code. For structures that satisfy the requirement of the specification, earthquake force reduction can be achieved just query parameter variables. This way is relatively simple compared with the way of specific calculation formula is given in application.

Previous studies showed that the reduction coefficient of horizontal seismic action mainly relationship with site conditions, natural period of structure, damping characteristics of upper structure and foundation [5]. So, this article thought that code selected natural period and damping ratio of structure as variables more comprehensive and reasonable than separately selected natural period or damping ratio to consider the influence of the SSI to seismic force. And we suggest that seismic code should give the parameter variables with lookup table of statistical significance from comprehensive use and ease of operation.

\section{Reduction Factor Distribution Along the Structure Height}

Reduction factor distribution along the structure height of Chinese mainland code has two cases: in structures with height-width-ratio less than 3 , each floor all use the same reduction factor of horizontal seismic shear; in structures with height-width-ratio is not less than 3 , the seismic shear of the structural bottom may be reduced according to provisions, that of the top may not reduced, and that of the middle floors may be reduced according to the linear interpolation values. At the same time, Chinese mainland code has given the reduced horizontal shear of all floors shall satisfy the requirements.

Taiwanese code implied that earthquake shear along the height of structure with the same reduction factor. At the same time, Taiwanese code has given the allowable relative lateral displacement angle of between floors shall satisfy the requirements.

In Chinese mainland code, the seismic shear of each floor need to reduce, and with reduced floor seismic shear calculated the displacement of each floor [6]. So, through this method to calculate floor displacement will decrease, that inconsistent with existing research results that "because the soil-structure interaction, the lateral displacement of structure possible increase". In conclusion, from the reduction factor of seismic response distribution along the structure height and reduced floor displacement, this study found that code given the limits on lateral displacement of the structure is more reasonable. Therefore, we suggest that the Chinese mainland code should have the reduction calculation method of seismic shear, but also should give the limit requirements of lateral displacement of a structure.

\section{CONCLUSION AND SUGGESTION}

For effects of soil-structure interaction, the Chinese mainland code and Taiwanese code are compared, the similarities and differences of two codes are summarized. The direction of modifying current Chinese mainland seismic code and the content of this paper are clarified. So, this paper suggests that Chinese mainland seismic code in terms of soilstructure interaction still need to do the following work:

1) Chinese mainland seismic code has too many restrictions for these buildings which should consider the SSI. And these stipulated structures are not enough clear or specific Therefore, we should conduct in-depth research and redefine for the application scope of SSI provisions. This paper suggests that we should combine with the actual situation of our country and contrast the use conditions of seismic shear reduction method, and comprehensive give the definite structure which consider soil-structure interaction effect.

2) For both simple and comprehensive embody influence factors of SSI, this paper suggests that Chinese mainland seismic code should study the influence of the interaction on natural period and damping ratio of structure, and select structural period and damping ratio as variables to consider the influence of SSI to seismic force. At the same time it should give the parameter variable lookup table of statistical significance.

3) Taiwanese code does not consider the change of reduction factor along the structure height, but the code under the strict control of structural lateral displacement angle to make up for the adverse effects. However, for structures whose height-width-ratio is not less than 3 , Chinese mainland seismic code stipulated that each floor of structure adopted different reduction factor. But Chinese mainland seismic code without considered the seismic response of the top floors may be increase. This paper suggests that Chinese mainland seismic code should consider the second-order effect which caused by 
SSI effect, and give modified lateral displacement of the structure.

\section{ACKNOWLEDGMENT}

This study is financially supported by

Basic Research Fund of Institute of Earthquake Science China Earthquake Administration (2014IESLZ04) and National Natural Science Foundation of China (No. 41472297).

\section{REFERENCES}

[1] Housing and Urban-Rural Development of the People's Republic of China, Code for Seismic Design of Buildings GB50011-2010. Beijing: Building Industry Press of China, 2010.

[2] Construction Management Department, Code and Explanation for Seismic Design of Buildings. Taipei: Construction Management Group, 2011.

[3] X. K. Guo, C. Y. Wei, G. Q. Li, K. S. Cai. "Comparison of building seismic design codes between Mainland and Taiwan,” 5th ed., vol. 12. Progress in Steel Building Structures, 2010, pp.52-62.

[4] K. S. Wang, Y. W. Wang. "Advice and instructions of industrial and civil architecture seismic design code about soil-structure interaction,” vol. 2. Building Science, 1985, pp.17-25.

[5] K. S. Wang, Y. W. Wang. "Background information of industrial and civil architecture seismic design code about soil-structure interaction," vol. 1. Earthquake Resistant Engineering, 1986, pp.36-41.

[6] H. Li, Y. M. Li, M. Lai. "Study on discount rate of horizontal seismic action under consideration of soil-structure dynamic interaction,” 1st ed., vol. 16. World Information on Earthquake Engineering, 2000, pp.65-71. 